\title{
Right transthoracic approach for robotic left main stem bronchus sleeve resection
}

Facundo Iriarte, MD, ${ }^{\mathrm{a}}$ Abbas E. Abbas, MD, ${ }^{\mathrm{b}}$ Roman Petrov, MD, ${ }^{\mathrm{a}, \mathrm{c}}$ Charles T. Bakhos, MD, ${ }^{\mathrm{c}}$ and Stacey Su, MD, ${ }^{\text {a }}$ Philadelphia, Pa, and Providence, RI

\footnotetext{
From the ${ }^{\mathrm{a} D e p a r t m e n t ~ o f ~ S u r g i c a l ~ O n c o l o g y, ~ F o x ~ C h a s e ~ C a n c e r ~ C e n t e r, ~ P h i l a d e l p h i a, ~ P a ; ~}{ }^{\mathrm{b}}$ Thoracic Surgery, Warren Alpert Medical School of Brown University, Providence, RI; ${ }^{\mathrm{c}}$ Department of Thoracic Medicine and Surgery, Temple University Hospital, Philadelphia, Pa.

Disclosures: The authors reported no conflicts of interest.

The Journal policy requires editors and reviewers to disclose conflicts of interest and to decline handling or reviewing manuscripts for which they may have a conflict of interest. The editors and reviewers of this article have no conflicts of interest.

Received for publication May 5, 2021; accepted for publication July 8, 2021; available ahead of print July 17, 2021.

Address for reprints: Abbas E. Abbas, MD, 593 Eddy St, APC 431, Providence, RI 02903 (E-mail: abbas.abbas@ brown.edu).

JTCVS Techniques 2021;10:572-4

2666-2507

Copyright (c) 2021 The Authors. Published by Elsevier Inc. on behalf of The American Association for Thoracic Surgery. This is an open access article under the CC BY-NC-ND license (http://creativecommons.org/licenses/bync-nd/4.0/).

https://doi.org/10.1016/j.xjtc.2021.07.005
}

- Video clip is available online.

A 43-year-old female patient had a proximal left main stem bronchus (LMSB) lesion identified 2 years previously on a computed tomography scan of the chest (Figure 1) during workup for severe asthma. The lesion was debrided via rigid bronchoscopy by a pulmonologist before surgical referral. Pathology revealed a well-differentiated neuroendocrine tumor. A gallium dotatate scan reported uptake in a subcarinal lymph node with a standardized uptake value of 13.8. Flexible bronchoscopy with endobronchial ultrasound was performed 3 weeks before surgical resection, and the base of the tumor was tattooed at the time with vital blue dye to facilitate its identification at the time of resection and allow visible margin assessment. Endobronchial ultrasoundguided biopsy confirmed isolated subcarinal lymph node involvement.

\section{Anesthesia Considerations}

We planned a right robotic thoracoscopic approach. Intraoperative ventilation to the left lung was accomplished with 6-mm single lumen wire-reinforced tube (Fuji Systems Corporation. Tokyo, Japan). A similar tube was available at the bedside for cross-field ventilation through a separate thoracoscopic port but was not needed. Two venous central catheters were placed in the right internal jugular vein and

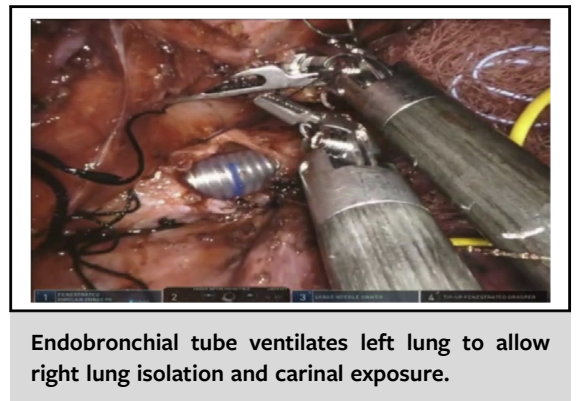

\begin{abstract}
CENTRAL MESSAGE
There are conflicting descriptions in the literature for the approach to a lung-sparing left main stem bronchus resection. We provide a detailed description of a robotic technique from the right side.
\end{abstract}

See Commentaries on pages 575 and 577. the right femoral vein in case extra corporeal membrane oxygenation (ECMO) was required.

\section{Surgical Technique}

The patient was placed in the left lateral decubitus position. Four 8-mm intercostal robotic ports were placed in the seventh to eighth intercostal space and one 12-mm assistant port at the tenth intercostal space mid-axillary line. Robotic instruments included bipolar Maryland (right arm), bipolar grasper (left arm), and tip-up grasper (retracting arm) for the dissection. The bronchus was divided with robotic scissors, and robotic needle driver was used for the anastomosis. The surgical field was controlled with a remotely operated surgical irrigator system. The procedure was completed by the da Vinci Xi robot (Intuitive Surgical, Sunnyvale, Calif).

A capnothorax of $10 \mathrm{~mm} \mathrm{Hg}$ was achieved. After division of the mediastinal pleural reflection along the posterior hilum, the esophagus was mobilized posteriorly, exposing the distal trachea and mainstem bronchi. Subcarinal lymph node package was completely resected. Both the carina and 


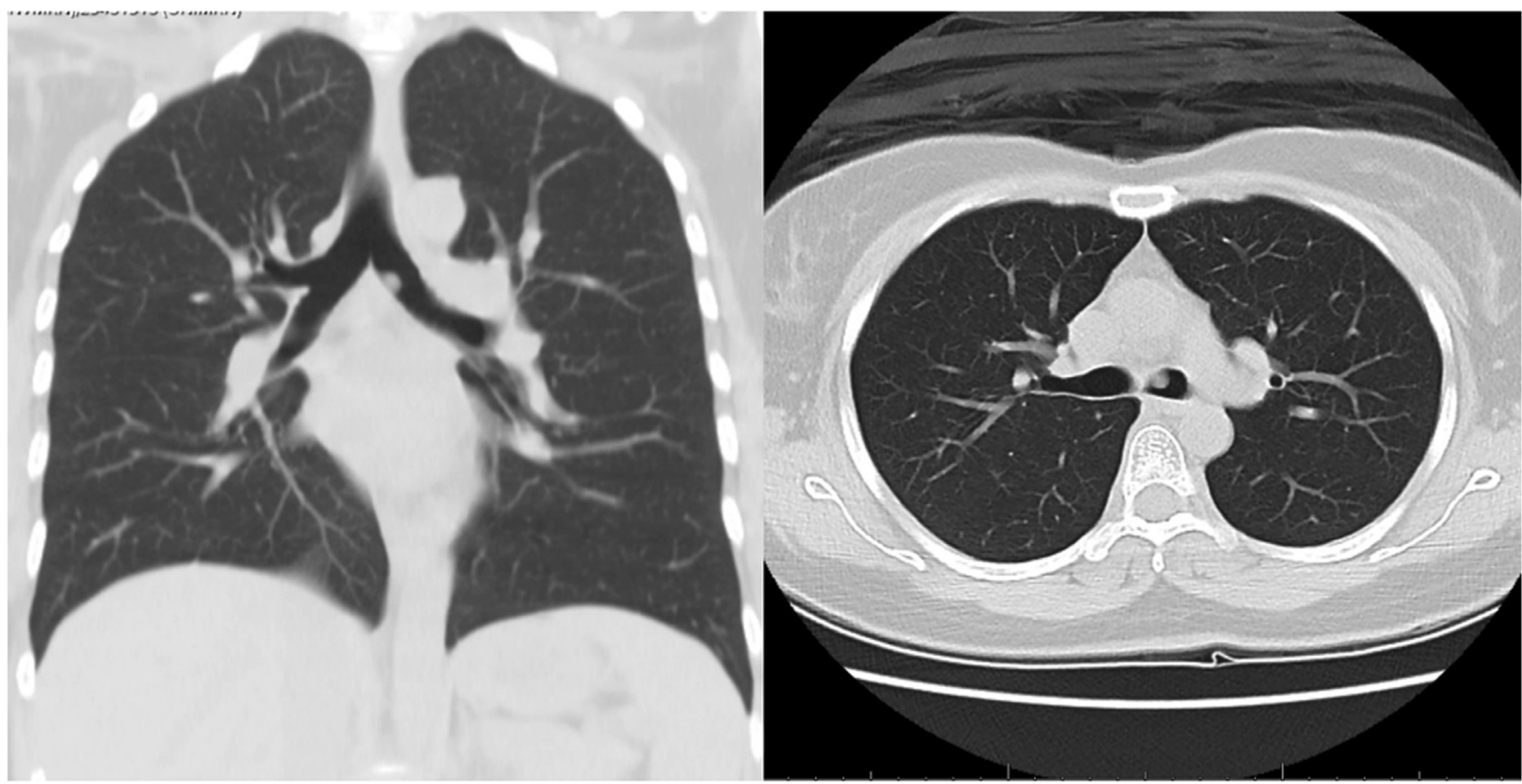

FIGURE 1. Computed tomography scan of the chest: left main stem bronchus nodule. Left: Coronal view. Right: axial view.

the proximal $3 \mathrm{~cm}$ of the LMSB were circumferentially dissected. It is important to protect the cuff of the endobronchial tube by pushing it as far as possible distally before dividing the bronchus. Based on the endobronchial appearance, we divided the proximal LMSB flush with the carina. We then resected the carinal end as a 5 -mm ring for proximal margin. Two stay sutures were placed in the distal LMSB bilaterally to prevent left intrathoracic retraction of the bronchus. After identifying the tattooed base of the tumor, we proceeded to resect a similar 5-mm ring for distal margin, about $3 \mathrm{~cm}$ from the carina and $1 \mathrm{~cm}$ proximal to the secondary carina. After removing the margins for frozen section, we completed the dissection and removal of the main bronchial segment. After confirming negative margins, a primary bronchial carinal end-to-end anastomosis was performed with 2 running absorbable 3-0 barbed sutures. The sutures were placed at the left membranouscartilaginous junction, and the anastomosis was performed in a running fashion first anteriorly then posteriorly. After we tested for an air leak, a pedicled pericardial thymic flap was developed and used to encircle the anastomosis (Video 1).

Final pathology revealed a 6-mm well-differentiated neuroendocrine tumor with negative resection margins. The patient was discharged after 2 days. The Fox Chase Cancer Center Institutional Review Board approved this study as IRB: 21-9916 on April 26, 2021. Informed consent was obtained before surgery.

\section{COMMENTS}

Due to its location adjacent to the aortic arch and main pulmonary artery, exposing the proximal LMSB is extremely challenging. It is well known that carinal exposure is easier from the right chest. However, for this operation, a right thoracic approach requires isolation of the right lung while operating on the left bronchus. Exposure from the left chest would require major dissection and retraction of the aorta and pulmonary artery with division of the ligamentum arteriosum. ${ }^{1,2}$ LMSB resection has also been described trans-sternally, on cardiopulmonary bypass. ${ }^{3}$ In addition, reports with or without ECMO for right-sided exposure have been described. ${ }^{4,5}$ However, to our knowledge, this is the first report of right thoracoscopic LMSB resection without ECMO.

Regarding ECMO for airway procedures, we believe it can be a valuable resource but that it does not come without potential downsides and risks. These include technical complications related to cannulation, flow problems that may necessitate reventilation at an importune time of the procedure, and the small but real increased risk of bleeding. In addition, of course, it requires extra time, personnel, and cost.

The technical approach is essentially the same as that with thoracotomy. We prefer to use barbed suture to facilitate the anastomosis and have found no increased risk of anastomotic complications with this material in more than 22 sleeve resections. ${ }^{6}$ Some surgeons advocate a mediastinoscopy before tracheal or carinal resections as a "release 


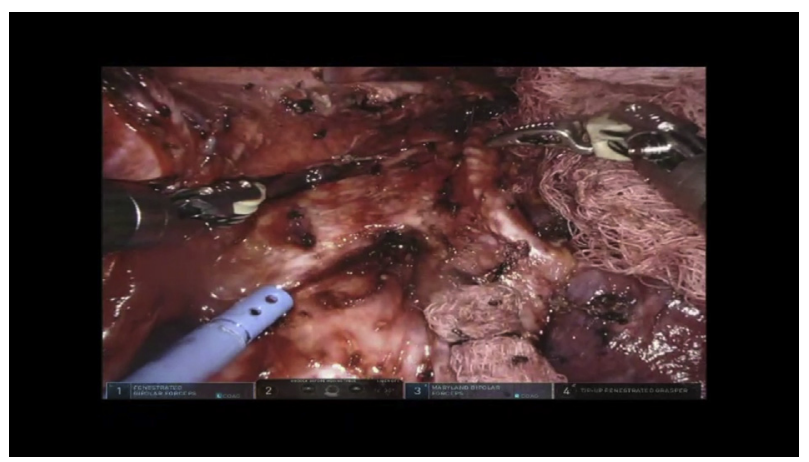

VIDEO 1. Robotic LMSB lung-sparing sleeve resection. Right transthoracic approach. Video available at: https://www.jtcvs.org/article/S26662507(21)00475-2/fulltext.

maneuver" of the trachea and main stem bronchi to help reduce tension at the anastomosis. However, one benefit of the robotic platform is the ability to use bimanual wristed dissection to replicate this same anterior airway dissection internally, thus avoiding an extra neck incision and procedure. In fact, we find that the robotic approach using the left bronchial intubation technique allows excellent exposure of the carina and LMSB while avoiding the potential disadvantages of ECMO.

\section{CONCLUSIONS}

We provide a detailed description of the surgical technique with anesthesia considerations for right roboticassisted lung-sparing LMSB resection. This may be of value for the thoracic surgery community when planning a similar approach.

\section{References}

1. Ragusa M, Vannucci J, Cagini L, Daddi N, Pecoriello R, Puma F. Left main bronchus resection and reconstruction. A single institution experience. J Cardiothorac Surg. 2012;7:29.

2. Caviezel C, Koersgen F, Weder W, Inci I. Left main bronchus sleeve resection with reconstruction of neolobar carina. J Thorac Cardiovasc Surg. 2017;154:370-2.

3. Kang MK, Kang DK, Hwang YH. Successful sleeve resection of bronchial carcinoid under veno-venous ECMO. Thorac Cancer. 2019;10:2319-21.

4. Newton JR, Grillo HC, Mathisen DJ. Main bronchial sleeve resection with pulmonary conservation. Ann Thorac Surg. 1991;52:1272-80.

5. Cerfolio RJ, Deschamps C, Allen MS, Trastek VF, Pairolero PC. Mainstem bronchial sleeve resection with pulmonary preservation. Ann Thorac Surg. 1996;61:1458-62; discussion 1462-1463.

6. Mazzei M, Abbas AE. Why comprehensive adoption of robotic assisted thoracic surgery is ideal for both simple and complex lung resections. J Thorac Dis. 2020; 12:70-81. 